\title{
Predictor of Metabolic Syndrome: A community study from Urban Delhi, India
}

\author{
Astha Bansal ${ }^{1}$ \\ P.C. Joshi ${ }^{2}$
}

\begin{abstract}
The aim of the present study is to assess and compare the presence of metabolic syndrome using IDF and Modified NCEP ATPIII criteria among Sunni Muslim of Delhi and to determine the optimal cut off values of different parameters for the detection of metabolic syndrome. A total of, 406 individuals (125 men, 281women) aged 35-65 years were recruited. Anthropometric, blood pressure and laboratory investigations were performed following the standard protocols. Receiver operating characteristics (ROC) curves of waist circumference, serum triglycerides, High density lipoprotein cholesterol, systolic and diastolic blood pressure and fasting blood glucose were created for the determination of the metabolic syndrome and the area under curve (AUC) was evaluated to determine the predictive efficiency of each variable of metabolic syndrome. The cut off values of each parameter with corresponding sensitivity, specificity, Youden index and likelihood ratios were estimated.

The overall metabolic syndrome assessed through Modified NCEP ATP III was $75.12 \%$ while through IDF criterion it was $75.36 \%$. Majority of the participants were equally identified by both definitions. The metabolic syndrome was higher in women as compare to men using both the criteria. The area under curve (AUC) shows that serum triglycerides have highest predictive ability for metabolic syndrome in modified NCEP ATP III and IDF. The population specific cut off values of different variable to detect metabolic syndrome was formed. Although these result may not apply to rest of Indian population due to multi ethnicity but similar studies with large sample size to find the cut off values of parameter for metabolic syndrome is needed for better detection and prevention.
\end{abstract}

Keywords: Sunni Muslims, Urban Population ,Metabolic Syndrome

\section{Introduction}

The presence of metabolic syndrome is rapidly increasing in India (Prasad et al., 2011). Approximately one third of urban South Asians have evidence of the metabolic syndrome (Misra \&

\footnotetext{
${ }^{1}$ M.Phil, Senior Research Scholar, Department of Anthropology, University of Delhi, asthabansal8@gmail.com
} 2 M.Phil, PhD, Professor, Department of Anthropology, University of Delhi, India, pcjoshi@anthro.du.ac.in 
Bansal, A., Joshi, P.C. (2015). Predictor of Metabolic Syndrome: A community study from Urban Delhi, India. International Journal of Human Sciences, 12(1), 1451-1462. doi: 10.14687/ijhs.v12i1.3289

Khurana, 2009). The rapid increase of metabolic factor in urban Indians is due to marked change in diet, sedentary lifestyle, urbanization and mechanization (Misra \& Khurana, 2009; Prasad et al., 2010; Wasir et al., 2004). In Asian Indians, increasing pool of the metabolic syndrome is a reason for concern since it may convert to type 2 diabetes mellitus (T2DM) and cardiovascular disease (CVD) if effective interventions are not applied (Gupta \& Misra, 2007 ; Misra \& Misra 2003). Metabolic syndrome is a complex condition arriving due to interplay between environmental and genetic factors operating differentially in different populations. Numerous studies have reported the inadequacy of the current definitions of metabolic syndrome in characterizing non-caucasian populations ( Tillin et al., 2009 ; Tan et al., 2004 ; Takeuchi et al., 2005; Sone et al., 2005) either over or underestimating the risk in certain ethnic group and even some research indicate that atherogenic dyslipidemia, glucose intolerance, subclinical inflammation and endothelial dysfunction are proportionately higher in Asian Indians than Caucasians (Mohan et al.,2007; Rao et al.,2005). Unfortunately, representative data to monitor cardiovascular risk factors is lacking in India (Anjana et al., 2011; Shah \& Mathur 2010). For assessments of metabolic syndrome in a population, a total of five definitions have been developed over the last decade (Misra \& Vikram, 2008). Worldwide, two definitions are most popular, given by the National Cholestrol Education Program, Adult Treatment Panel III (NCEP ATP III) and International Diabetes Federation (IDF). However, according to the IDF, waist circumference is a mandatory variable containing ethnic group specific cut offs, but whether the latest IDF definitions predict cardiovascular in Asian Indian and other Asian Indian population is not yet clear (Wasir et al., 2008). Further, whether all the variables of metabolic syndrome are equally important or some are more important than other is also a contentious issue (Misra \& Vikram, 2008). Hence, considering the above, the present study has two important research question: first to update the presence of metabolic syndrome among Sunni Muslim of Delhi using International Diabetes Federation (IDF) and revised NCEP-ATPIII guideline and to investigate the concordance between the two definitions; second to identify the stronger predictor of metabolic syndrome and also determine the population specific cut off point of metabolic variables.

\section{Material and methods}

The present study was conducted among Sunni Muslim of Delhi, India consisting of a total of 406 subjects (125 men, 281 women) under the age group of 35-65 years. The information such as lifestyle, socio demographic, medical history was collected through pretested interview schedule. Waist circumference (WC) was measured according to standard procedure (Lohman et al., 1988). Measurement was conducted by trained personnel. The physiological measurement includes systolic blood pressure (SBP), diastolic bold pressure (DBP). Two consecutive reading were taken as recommended by the American Heart Association, 1981. $5 \mathrm{~mL}$ intravenous blood sample after 12 hours of fasting was drawn after obtaining written informed consent from all the recruited individuals by trained personnel. Fasting blood samples were drawn to analyze the levels of Fasting glucose (FG), triglycerides (TG), high density lipoprotein cholesterol (HDL-C). Lipid parameters were estimated using Spectrophotometry technique and commercial kits (Randox Laboratories Ltd.)

In the present study, diagnosis of metabolic syndrome was based on two methods: Firstly modified NCEP ATP III criteria (Heng et al., 2006) which defines metabolic syndrome by the presence of three or more of the following risk determinants: central obesity [WC $>90 \mathrm{~cm}$ in men or WC> 80 
Bansal, A., Joshi, P.C. (2015). Predictor of Metabolic Syndrome: A community study from Urban Delhi, India. International Journal of Human Sciences, 12(1), 1451-1462. doi: 10.14687/ijhs.v12i1.3289

in women); elevated TG ( $\geq 150 \mathrm{mg} / \mathrm{dl})$, HDL-C $<40 \mathrm{mg} / \mathrm{dl}$ in men, $<50 \mathrm{mg} / \mathrm{dl}$ in women), SBP $\geq 130 \mathrm{mmHg}$ and/ or $\mathrm{DBP} \geq 85 \mathrm{mmHg}$ or medical treatment of previously diagnosed hypertension, FG $>110 \mathrm{mg} / \mathrm{dl}$. Secondly Subjects were defined as Metabolic syndrome by IDF (Zimmet et al., 2005) presence of central obesity with WC $>90 \mathrm{~cm}$ in men or WC $>80 \mathrm{~cm}$ in women plus any two of the following: elevated TG $>150 \mathrm{mg} / \mathrm{dl}$ or specific treatment for this lipid abnormality, HDL-C $<40 \mathrm{mg} / \mathrm{dl}$ in men, $<50 \mathrm{mg} / \mathrm{dl}$ in women or medical treatment of this lipid abnormality, SBP $>130$ and or DBP $>85 \mathrm{mmHg}$ or medical treatment of previously diagnosed hypertension, fasting glucose $>100 \mathrm{mg} / \mathrm{dl}$ or previously diagnosed type 2 diabetes.

The present study was approved by the Ethical Committee, Department of Anthropology, University of Delhi. Prior to start of study, written consent was taken from all the study subjects.

\section{Statistical Analysis}

Statistical analyses were performed using SPSS version 17. Receiver operating characteristics (ROC) curves of TG, HDL-C, WC, SBP,DBP and FG were created for the prediction of metabolic syndrome and area under the ROC curve were used to evaluate the predictive efficiency of each metabolic syndrome parameter. The area under the ROC curve obtained was compared of different samples using the method described by Hanley \&McNeil, 1982. Several indexes were calculated to obtain the best optimal cut-off point on the curve for the different parameters. The minimal cut-off value was calculated using the distance of the point closest to $(0,1)$ on the ROC curve formula:

$$
\text { Square root }\left[(1-\text { Sensitivity })^{2}+(1-\text { specificity })^{2}\right] \text { (Perkin \& Schisterman, 2006) }
$$

The Youden index was calculated using $[J=$ sensivity - (1- specificity) (Bohning et al., 2008), the maximum value $J$ can attain 1 , when the test is perfect and the minimum value is 0 , the test has no diagnostic value. Moreover, positive likelihood ratio (sensitivity/1 -specificity) were calculated along with cut off value and Youden index; likelihood ratios $>1$ indicate association with the disease, whereas ratios $<1$ indicate association with the absence of the disease (Bewick et al., 2004). Different cut points in the selected variables and the corresponding sensitivity and specificity were also estimated. The kappa statistics was used to determine the agreement between the two diagnostic criteria i.e. modified NCEP ATP III and IDF

\section{Results}

Table1: Sex wise distribution of individuals with and without metabolic syndrome based on NCEP ATP III and IDF criteria among Sunni Muslims of Delhi

\begin{tabular}{|c|c|c|c|c|c|c|}
\hline \multirow[t]{2}{*}{$\begin{array}{l}\text { Metabolic } \\
\text { Syndrome }\end{array}$} & \multirow{2}{*}{$\begin{array}{l}\text { NCEP } \\
\text { ATP III } \\
\mathbf{N}(\%) \\
(\mathrm{N}=406)\end{array}$} & \multirow{2}{*}{$\begin{array}{l}\text { IDF } \\
\mathbf{N}(\%) \\
\mathrm{N}=406)\end{array}$} & \multicolumn{2}{|c|}{$\begin{array}{c}\text { Men } \\
\text { N (\%) }\end{array}$} & \multicolumn{2}{|l|}{$\begin{array}{l}\text { Women } \\
\mathbf{N}(\%)\end{array}$} \\
\hline & & & $\begin{array}{l}\text { NCEP } \\
\text { ATP III } \\
(\mathrm{N}=125)\end{array}$ & $\begin{array}{l}\text { IDF } \\
(N=125)\end{array}$ & $\begin{array}{l}\text { NCEP } \\
\text { ATP III } \\
(\mathrm{N}=281)\end{array}$ & $\begin{array}{l}\text { IDF } \\
(\mathrm{N}=281)\end{array}$ \\
\hline Absent & $101(24.87)$ & $100(24.63)$ & $38(30.4)$ & $41(32.8)$ & $63(22.41)$ & $59(20.99)$ \\
\hline Present & $305(75.12)$ & $306(75.36)$ & $87(69.6)$ & $84(67.2)$ & $218(77.58)$ & $222(79)$ \\
\hline
\end{tabular}


Bansal, A., Joshi, P.C. (2015). Predictor of Metabolic Syndrome: A community study from Urban Delhi, India. International Journal of Human Sciences, 12(1), 1451-1462. doi: 10.14687/ijhs.v12i1.3289

Among 406 subjects (281 women and 125 men), metabolic syndrome was diagnosed in $305(75.12 \%)$ and $306(75.36 \%)$ subjects according to the modified NCEP ATP III and IDF criteria, respectively. After stratification by gender, $87(67.6 \%)$ men and $218(77.58 \%)$ women, $87(67.2 \%)$ men and 222(79\%) women had metabolic syndrome according to the modified NCEP ATPIII and IDF criteria. Presence of metabolic syndrome was more in women as compared to men. NCEP ATP III guideline formed to be better than IDF guideline for men as it identified 3 more men for metabolic syndrome. However among female 4 participants were diagnosed by IDF criteria but missed by modified NCEP ATP III. Majority of the subjects were identified equally by both definition as shown by kappa statistics was $0.916 \pm .023(\mathrm{p}<.001)$ for the total population, $0.916 \pm .029(\mathrm{p}<.001)$ for women and $0.908 \pm .040(\mathrm{p}<.001)$ for men.

Table 2: Percentage of component of metabolic syndrome among Sunni Muslims of Delhi

\begin{tabular}{|c|c|c|c|}
\hline Variable & Women N (\%) & Men N (\%) & Overall N (\%) \\
\hline $\begin{array}{ll}\text { WC } & (\text { Men }>90 \mathrm{~cm} ; \\
\text { Women }>80 \mathrm{~cm}) & \end{array}$ & $272(96.79)$ & $110(88)$ & $382(94.08)$ \\
\hline $\mathrm{TG} \geq 150 \mathrm{mg} / \mathrm{dl}$ & $171(60.85)$ & $86(68.8)$ & $257(63.30)$ \\
\hline $\begin{array}{l}\text { Low HDL-C }(\text { Men }<40 \mathrm{mg} / \mathrm{dl} \text {; } \\
\text { Women }<50)\end{array}$ & $190(67.61)$ & $37(29.6)$ & $227(55.91)$ \\
\hline $\mathrm{SBP}(\geq 130 \mathrm{mmHg})$ & $197(70.10)$ & $90(72)$ & $287(70.68)$ \\
\hline $\mathrm{DBP}(\geq 85 \mathrm{mmHg})$ & $135(48.04)$ & $77(61.6)$ & $212(52.21)$ \\
\hline $\mathrm{FG}((>100 \mathrm{mg} / \mathrm{dl})$ & $110(39.14)$ & $56(44.8)$ & $166(40.88)$ \\
\hline $\mathrm{FG}(>110 \mathrm{mg} / \mathrm{dl})$ & $75(26.69)$ & $44(35.2)$ & $227(55.91)$ \\
\hline
\end{tabular}

The presence of metabolic syndrome for the central obesity with waist circumference was $96.79 \%$ for women while $88 \%$ for men, overall $94.08 \%$ have central obesity. In the present study, $60.85 \%$ of women had high triglycerides, while $68.8 \%$ of men had high triglycerides; overall $63.30 \%$ had high triglycerides. $67.65 \%$ of women had low HDL Cholestrol while $29.6 \%$ of men had low HDL Cholestrol; overall 55.911\% had low HDL Cholestrol. 70.10\% of women had high Systolic blood pressure, while $72 \%$ of men had high systolic blood pressure; overall $70.68 \%$ had high systolic blood pressure. $48.04 \%$ of women had high diastolic blood pressure while $61.6 \%$ of men had high diastolic blood pressure; overall $55.21 \%$ had high diastolic blood pressure. $39.14 \%$ of women and $44.8 \%$ of men had high fasting glucose using IDF criteria whereas $26.69 \%$ women and $35.2 \%$ of men had high fasting glucose using NCEP ATP III criteria. More subjects having high fasting glucose were identified using IDF than the NCEP ATP III criteria.

Table 3: Area under the ROC curve of metabolic variables (HDL-C, TG, WC, SBP, DBP and FG)

\begin{tabular}{|l|l|l|l|l|}
\hline Variables & $\begin{array}{c}\text { Modified NCEP } \\
\text { ATP-III } \\
\text { ROC curve area } \\
(95 \% \mathrm{CI})\end{array}$ & $\mathrm{p}$ value & $\begin{array}{c}\text { IDF } \\
\text { ROC curve area } \\
(95 \% \mathrm{CI})\end{array}$ & p value \\
\hline HDL-C & & & & \\
\hline Women & $0.763(0.704-0.822)$ & .000 & $0.724(0.658-0.789)$ & .000 \\
\hline Men & $0.634(0.539-0.729)$ & 0.017 & $0.604(0.506-0.703)$ & 0.049 \\
\hline
\end{tabular}


Bansal, A., Joshi, P.C. (2015). Predictor of Metabolic Syndrome: A community study from Urban Delhi, India. International Journal of Human Sciences, 12(1), 1451-1462. doi: 10.14687/ijhs.v12i1.3289

\begin{tabular}{|l|l|l|l|l|}
\hline TG & & & & \\
\hline Women & $0.849(0.805-0.894)$ & .000 & $0.829(0.776-0.881)$ & .000 \\
\hline Men & $0.813(0.729-0.897)$ & .000 & $0.776(0.674-0.858)$ & .000 \\
\hline WC & & & & \\
\hline Women & $0.627(0.548-0.707)$ & .002 & $0.647(0.567-0.731)$ & .001 \\
\hline Men & $0.669(0.554-0.784)$ & .003 & $0.729(0.620-0.838)$ & .000 \\
\hline SBP & & & & \\
\hline Women & $0.697(0.621-0.773)$ & .000 & $0.727(0.652-0.802)$ & .000 \\
\hline Men & $0.757(0.659-0.854)$ & .000 & $0.738(0.640-0.835)$ & .000 \\
\hline DBP & & & & \\
\hline Women & $0.664(0.593-0.735)$ & .000 & $0.680(0.609-0.751)$ & .000 \\
\hline Men & $0.737(0.637-0.838)$ & .000 & $0.718(0.616-0.819)$ & .000 \\
\hline FG & & & & \\
\hline Women & $0.742(0.683-0.803)$ & .000 & $0.771(0.712-0.829)$ & .000 \\
\hline Men & $0.810(0.730-0.889)$ & .000 & $0.775(0.686-0.864)$ & .000 \\
\hline
\end{tabular}

Serum triglycerides for men and women had highest predictive ability for metabolic syndrome in both criteria. According to modified NCEP ATP III area under curve for women was 0.849 with 95\% CI (0.805- 0.894) while among men was 0.813 with 95\% CI (0.729-0.897) and according to IDF criteria area under the curve for women was $0.829(0.776-0.881)$ while among men the area under curve was $0.776(0.674-0.888)$. Area under the curve for triglycerides differed significantly (men vs female, $\mathrm{p}<0.05$ ). After Triglycerides, the highest predictive ability for metabolic syndrome is fasting glucose whose area under the curve was 0.810 with $95 \% \mathrm{CI}(0.730-0.889)$ among men using NCEP ATP III while 0.775 95\% CI (0.686-0.864) among men using IDF criteria.

Table 4: Cut off value with sensivity, specificity, distance to ROC, Youden index and likelihood ratio using NCEP ATP III criteria

\begin{tabular}{|l|l|l|l|l|l|l|}
\hline Variable & $\begin{array}{l}\text { Optimal cut } \\
\text { off point }\end{array}$ & Sensitivity & specificity & $\begin{array}{l}\text { Distance to } \\
\text { ROC }\end{array}$ & $\begin{array}{l}\text { Youden } \\
\text { Index }\end{array}$ & $\begin{array}{l}\text { likelihood } \\
\text { ratios }\end{array}$ \\
\hline Women & & & & & & \\
\hline TG & 149.5 & 75.9 & 11.11 & 0.271 & 0.641 & 6.77 \\
\hline HDL-C & 45.5 & 74.6 & 33 & 0.416 & 0.418 & 2.260 \\
\hline WC & 95.5 & 63.3 & 42.9 & 0.564 & 0.204 & 1.475 \\
\hline SBP & 129.5 & 78.9 & 39.7 & 0.449 & 0.392 & 1.987 \\
\hline DBP & 83.5 & 55.5 & 27 & 0.52 & 0.28 & 2.05 \\
\hline FG & 88.62 & 68.8 & 30.2 & 0.52 & 0.28 & 2.05 \\
\hline Men & & & & & & \\
\hline TG & 167.5 & 75.9 & 18.4 & 0.303 & 0.575 & 4.12 \\
\hline HDL-C & 40.5 & 94.7 & 52.9 & 0.531 & 0.418 & 1.790 \\
\hline WC & 99.5 & 70.1 & 36.8 & 0.474 & 0.333 & 1.90 \\
\hline SBP & 130.5 & 69 & 28.9 & 0.423 & 0.401 & 2.387 \\
\hline DBP & 83.5 & 74.7 & 31.6 & 0.404 & 0.404 & 2.363 \\
\hline FG & 95.98 & 66.7 & 18.4 & 0.38 & 0483 & 3.625 \\
\hline
\end{tabular}


Bansal, A., Joshi, P.C. (2015). Predictor of Metabolic Syndrome: A community study from Urban Delhi, India. International Journal of Human Sciences, 12(1), 1451-1462. doi: 10.14687/ijhs.v12i1.3289

The optimal cut point is calculated as minimal distance in ROC curve using formula: square root [(1 - Sensitivity $)^{2}+(1-\text { specificity })^{2}$, the optimal cut off point of triglycerides among women was $149.5 \mathrm{mg} / \mathrm{dl}$ with $75.9 \%$ of sensitivity and $11.11 \%$ of specificity, while among men the cut off point was $167.5 \mathrm{mg} / \mathrm{dl}$ with $75.9 \%$ sensitivity and $18.4 \%$ specificity. For women, HDL-C cut off of $45.5 \mathrm{mg} / \mathrm{dl}$ with $74.5 \%$ sensitivity and $33 \%$ specificity, while among men $40.5 \mathrm{mg} / \mathrm{dl}$ was the optimal cut-off with $94.7 \%$ sensivity and $52.9 \%$ specificity for HDL-C. The optimal cut off for waist circumference in women was $95.5 \mathrm{~cm}$ with $63.3 \%$ sensitivity and $42.9 \%$ specificity while among men $99.5 \mathrm{~cm}$ was the optimal cut off value with $70.1 \%$ sensitivity and $36.8 \%$ specificity. The optimal cut off for systolic blood pressure for women was $129.5 \mathrm{~mm} / \mathrm{Hg}$ with $78.9 \%$ sensitivity and $39.7 \%$ specificity, while among men $130.5 \mathrm{~mm} / \mathrm{Hg}$ with $69 \%$ sensivity and $28.9 \%$ specificity. The optimal cut off for diastolic blood pressure in women was $83.5 \mathrm{~mm} / \mathrm{Hg}$ with $55.5 \%$ sensitivity and $27 \%$ specificity, while among men $83.5 \mathrm{~mm} / \mathrm{Hg}$ with $74.7 \%$ sensitivity and $31.6 \%$ specificity. The optimal cut off for blood fasting glucose for women is $88.62 \mathrm{mg} / \mathrm{dl}$ with $68.82 \%$ sensitivity and $30.2 \%$ specificity, while among men $95.98 \mathrm{mg} / \mathrm{dl}$ with $66.7 \%$ sensitivity and $18.4 \%$ specificity. For each cut off value Youden index and likelihood ratio was also calculated.

Figure 1:_ROC curves constructed to determine HDL-C, TG, WC, SBP, DBP and FG cut-off points for the detection of metabolic syndrome among Sunni Muslims of Delhi defined by Modified NCEP ATP III criteria

Women (HDL-C)

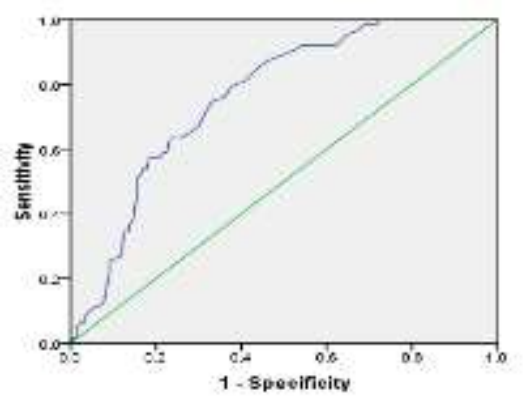

Women (TG)

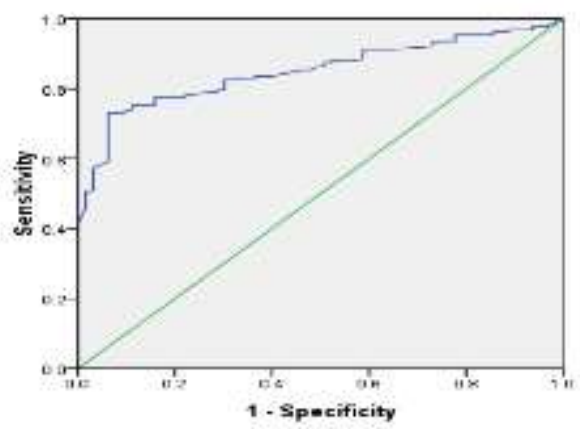

Women (WC)

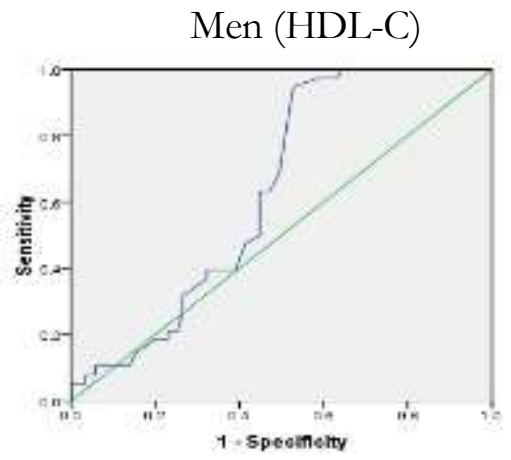

Men (TG)

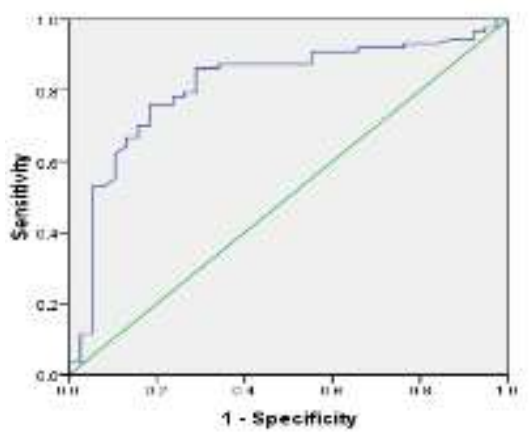

$\operatorname{Men}(\mathrm{WC})$ 
Bansal, A., Joshi, P.C. (2015). Predictor of Metabolic Syndrome: A community study from Urban Delhi, India. International Journal of Human Sciences, 12(1), 1451-1462. doi: 10.14687/ijhs.v12i1.3289

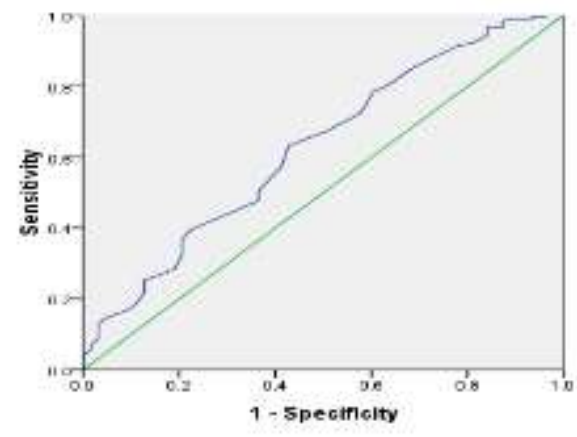

Women (SBP)

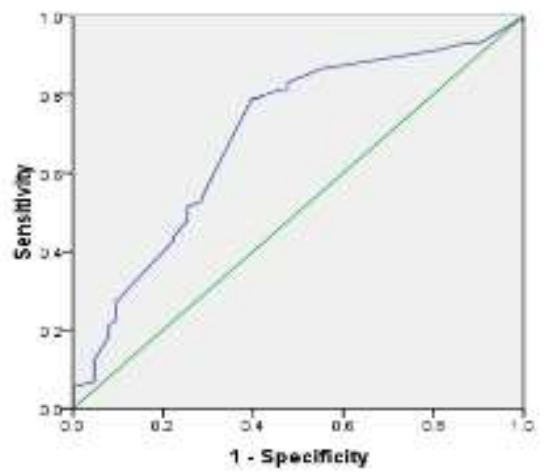

Women( DBP)

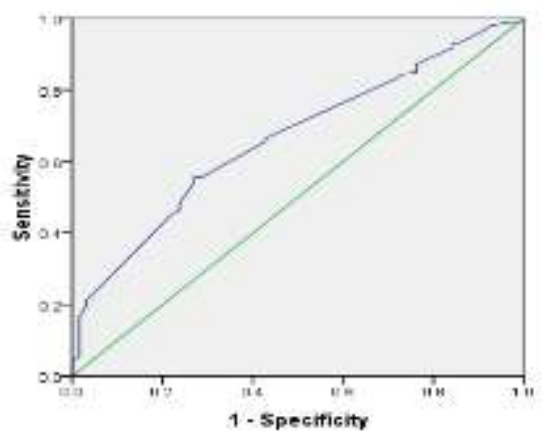

Women (FG)

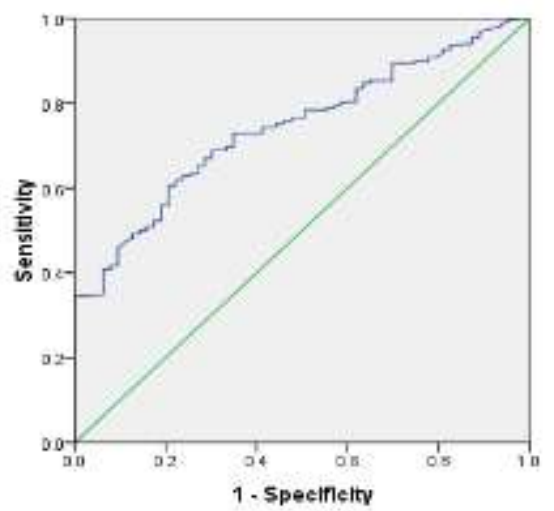

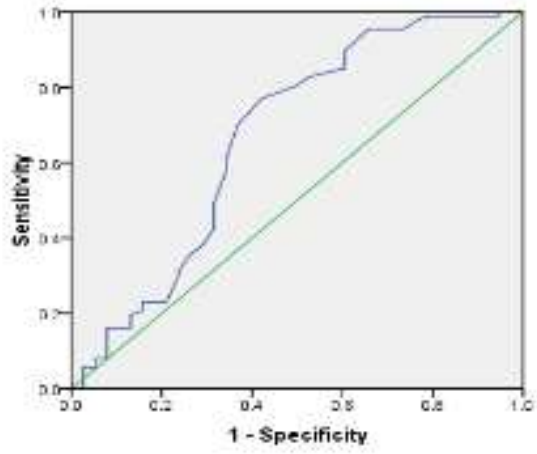

Men (SBP)

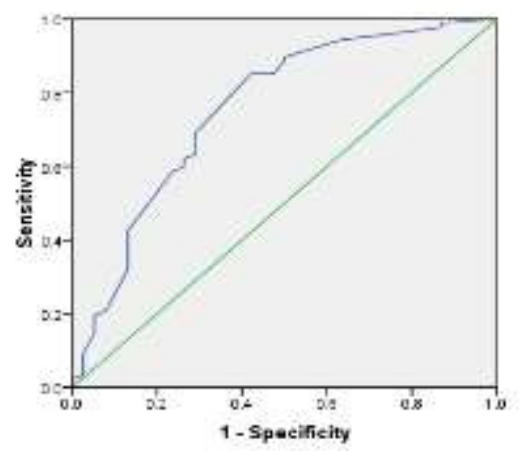

Men (DBP)

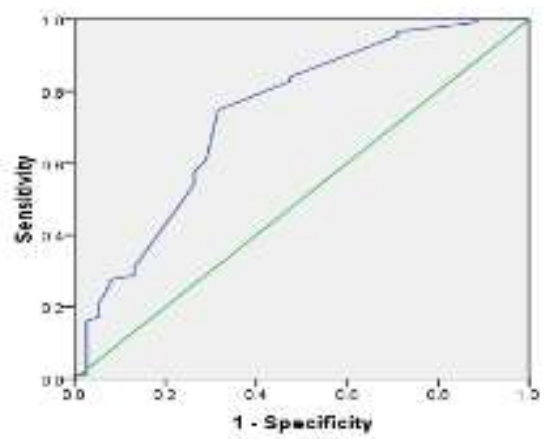

$\operatorname{Men}(\mathrm{FG})$

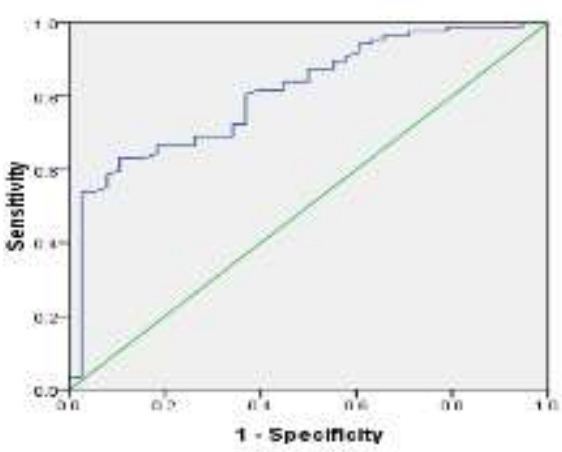


Bansal, A., Joshi, P.C. (2015). Predictor of Metabolic Syndrome: A community study from Urban Delhi, India. International Journal of Human Sciences, 12(1), 1451-1462. doi: 10.14687/ijhs.v12i1.3289

\section{Discussion}

This cross- sectional study was conducted in highly urbanized population of Delhi, a region with unique lifestyle and culture. A very high percentage of metabolic syndromes were assessed through Modified NCEP ATP III (75.12\%) and through IDF criterion (75.36\%).

Both the methods have approximately equal predictive ability to diagnose metabolic syndrome among Sunni Muslims of Delhi. Among the various components, hypertriglyceridemia showed highest predictive ability to diagnose metabolic syndrome in men and women. In the present study, the higher percentage of metabolic syndrome in women as compared to men was not a surprising observation. Since ninety six percentage of women were centrally obese (waist circumference $>80$ $\mathrm{cm}$ ) with higher percentage of low HDL Cholestrol, excessive weight has been the one of the major contributor of metabolic syndrome among women (Wasir JS et al., 2008). However, in some studies from India and abroad, women had a higher percentage of metabolic syndrome (Hydrie et al., 2009; Mabry et al., 2010; Khanam et al., 2011; Jesmin et al., 2012). Among women, metabolic changes is accompanying menopause which might increased the prevalence of metabolic syndrome in women. In spite of higher presence of metabolic syndrome in women, men are significantly associated with cardiovascular risk (Isles et al., 1992; Tunstall-Pedoe et al., 1997). Since it is unclear what factor protecting women against cardiovascular risk, but according to some studies women had protective effect of endogenous estrogens against atherosclerosis during premenopausal (Saltiki et al., 2008)

The serum triglycerides in men has higher cut off of $167.5 \mathrm{mg} / \mathrm{dl}$ as compared to standard cut off $150 \mathrm{mg} / \mathrm{dl}$. This is due to more central obesity in Asian Indians as compared to Caucasians (Gupta et al., 2004). Comparing serum triglycerides with different regions of country, the triglyceride show higher value in population of north (Gandhi, 1982), west (Jhala et al., 1998), south and eastern region (Goswami \& Bandopadhyaya, 2003). The serum triglycerides levels not only dependent on fat rich diet but also influenced by sedentary lifestyle and rich consumption of carbohydrates. The consumption of ghee( clarified butter) can also had an impact on lipid, since heating of ghee under pressure can covert the fatty acid of ghee in trance fatty acid which has atherogenic effect (Gupta \& Prakash, 1997). The cut off for HDL-C in men of $40.5 \mathrm{mg} / \mathrm{dl}$ had an optimal sensivity and specificity which is in accordance with the standard cut off required to define metabolic syndrome whereas among women the cut off value predicted is $45.5 \mathrm{mg} / \mathrm{dl}$ which is lower than standard cut off value. The cut off value for waist circumference is $95.5 \mathrm{~cm}$ for women and for men the optimal cut off value is $99.5 \mathrm{~cm}$. The cut off value of waist circumference is high than the standard cut off value for Asian Indian. The commonly used definitions to predict metabolic syndrome requires certain modification as waist circumference represent visceral fat, and several studies have shown the relationship to an increase risk of cardiovascular disease (Després et al., 2008; Chiba et al., 2007; Sam et al., 2009). Asian Indian have higher abdominal fat mass as compared to Caucasian and African American, the central obesity is been postulated as a leading modifiable cause of cardiovascular disease in Asia (Mohan \& Deepa, 2006)

The optimal cut off value for systolic and diastolic blood pressure is in accordance with cut off defined by standard criteria. The optimal cut off value of fasting blood sugar for women is $88.62 \mathrm{mg} / \mathrm{dl}$ while for men $95.98 \mathrm{mg} / \mathrm{dl}$. The cut off value of the present study is lower than standard cut of values. The fasting blood glucose has second highest predictive ability after triglycerides. Since the elevated fasting glucose concentration is associated with high risk for the progression to diabetes (Charles et al., 1991; Edelstein et al., 1997; Shaw et al., 1999; Alberti et al., 
Bansal, A., Joshi, P.C. (2015). Predictor of Metabolic Syndrome: A community study from Urban Delhi, India. International Journal of Human Sciences, 12(1), 1451-1462. doi: 10.14687/ijhs.v12i1.3289

1996) as well further cardiovascular disease (Alberti, 1996; Stamler et al., 1993; Balkau et al., 1998; Laakso \& Lehto, 1998), Further studies are required to elucidate the sex difference in cut off value of fasting blood glucose for the better detection of metabolic syndrome.

In conclusion, regardless of the metabolic syndrome definition the presence of metabolic syndrome is high among Sunni Muslim of Delhi. This reinforces the need for comprehensive preventive and control program. The present study results support the fact that the serum triglyceride was the strongest single predictor, which can efficiently indicate the presence of metabolic syndrome. The currently recommended cut points for waist circumference, triglyceride, and fasting blood sugar require some modification for better prediction.

\section{Acknowledgement}

Financial assistance to Astha Bansal from University Grant Commission (UGC), National Fellowship (No.F.159 June 2010/2010(NET)) and P. C. Joshi to University of Delhi, $R$ \& $D$ Grant (Dean(R)/ReD/2012/917) is gratefully acknowledged.

\section{References}

American Heart Association.(1981). Report of subcommittee of post graduate education committee recommendation for human blood pressure determination of sphygmomanometer. Circulation, 64: 510-599

Anjana, R.M., Ali, M.K., Pradeepa, R., Deepa, M., Datta, M., Unnikrishnan, R., et al. (2011) The need for obtaining accurate nationwide estimates of diabetes prevalence in India-Rationale for a national study on diabetes. Indian J Med Res 133,369-80.

Alberti, K.(1996) Impaired glucose tolerance — fact or fiction. Diabet Med 13, 6-8.

Bohning, D., Bohning, W., Holling, H. (2008) Revisiting Youden's index as a useful measure of the misclassification error in meta analysis of diagnostic studies. Statistical Methods in Medical Research $3,1-12$

Bewick, V., Cheek, L., Ball, J. (2004) Statistics review 13: receiver operating characteristics curves. Critical Care 8, 508-512

Balkau, B., Shipley, M., Jarrett, R.J., Pyorala, K., Pyorala, M., Forhan, A. et al.(1998) High blood glucose concentration is a risk factor for mortality in middle-aged non-diabetic men. 20-year follow-up in the Whitehall Study, the Paris Prospective Study, and the Helsinki Policemen Study.Diabetes Care 21, 360-367.

Chiba, Y., Saitoh, S., Takagi, S., Ohnishi, H., Katoh, N., Ohato, J., et al(2007)Relationship between visceral fat and cardiovascular disease risk factor: The Tanno and Sobetsu Study. Hypertens Res 30, 229-36.

Charles, M., Fontbonne, A., Thibult, N., Warnet, J.M., Rosselin, G., Eschwege, E. (1991) Risk factors for NIDDM in white population. Paris Prospective Study. Diabetes 40, 796-799 
Bansal, A., Joshi, P.C. (2015). Predictor of Metabolic Syndrome: A community study from Urban Delhi, India. International Journal of Human Sciences, 12(1), 1451-1462. doi: 10.14687/ijhs.v12i1.3289

Després, J.P., Lemieux, I., Bergeron, J., Pibarot, P., Mathieu, P., Larose, E., et al.(2008) Abdominal obesity and the metabolic syndrome: contribution to global cardiometabolic risk. Arterioscler Thromb Vasc Biol 28, 1039-49.

Edelstein, S., Knowler, W., Bain, R., Andres, R., Barrett-Connor, E., Dowse, G et al(1997) Predictors of progression from impaired glucose tolerance to NIDDM. An analysis of six prospective studies. Diabetes 46, 701-710.

Gupta, R., Deedwania, P.C., Gupta, A., Rastogi, S., Panwar, R.B., Kothari, K. (2004) Prevalence of metabolic syndrome in an Indian urban population. Int J Cardiol 97, 257-61.

Gupta, R., Misra, A. (2007) Type 2 diabetes in India: Regional disparities. Br J Diabetes Vasc Dis 7, 12-6.

Gandhi, B.M. (1982) Lipoprotein composition of normal healthy subjects in northern India; India J Med. Res 75,393-401

Gupta, R., Prakash, H.(1997) Assessment of dietary ghee intake with coronary heart disease and risk factor prevalence in rural male. J. Indian. Med Association 95, 67-69

Goswami, K., Bandopadhyaya, A.(2003) Lipid profile in middle class Bengali population of Kolkata. Indian journal of clinical biochemistry 18, 127-130

Hydrie, M.Z., Shera, A.S., Fawwad, A., Basit, A., Hussain, A. (2009) Prevalence of metabolic syndrome in urban Pakistan (Karachi): comparison of newly proposed International Diabetes Federation and modified Adult Treatment Panel III criteria. Metab Syndr Relat Disord 7,119-24.

Heng, D., Ma, S., Lee, J.J.M., Tai, B.C., Mak, K.H., Hughes, K., et al.(2006) Modification of the NCEP ATP III definitions of the metabolic syndrome for use in Asians identifies individuals at risk of ischemic heart disease. Atherosclerosis 186, 367-73.

Hanley, J.A., M.c.Neil, B.J. (1982) The meaning and use of the area under a receiver operating characteristic (ROC) curve. Radiology 143, 29-36.

Isles, C.G., Hole, D.J., Hawthorne, V.M., Lever, A.F. (1992) Relation between coronary risk and coronary mortality in women of the Renfrew and Paisley survey: comparison with men. The Lancet 339,702-6.

Jesmin, S., Islam, R., Islam, S., Mia, S., Sultana, S.N., Zaedi, S. et al. (2012) Comprehensive assessment of metabolic syndrome among Rural Bangladeshi Women. BMC Public Health 12,49.

Jhala, C.I., shaha, TK, Naik, B.K., Dalfda, J.D.(1998) A study of serum lipid profile part 1 establishment of normal reference value of serum lipid level in healthy vegetarian population of Gujarat. Ind J, clin biochem, 13, 1-7

Khanam, M.A., Qiu, C., Lindeboom, W., Streatfield, P.K., Kabir, Z.N., Wahlin, A.(2011)The Metabolic Syndrome: Prevalence, Associated Factors, and Impact on Survival among Older Persons in Rural Bangladesh. PLoS ONE 6, 20259 
Bansal, A., Joshi, P.C. (2015). Predictor of Metabolic Syndrome: A community study from Urban Delhi, India. International Journal of Human Sciences, 12(1), 1451-1462. doi: 10.14687/ijhs.v12i1.3289

Lohman, T., Roche, A. F. \& Martorell, R. (1988) Anthropometric Standardization Reference Manual. Human Kinetics Publication, Chicago.

Laakso, M., Lehto , S.(1998) Epidemiology of risk factors for cardiovascular disease in diabetes and impaired glucose tolerance. Atherosclerosis, 137,65-73.

Misra, A., Misra, R. (2003) Asian Indians and insulin resistance syndrome: Global perspective. Met Syndr Relat Disord 1, 277-85.

Misra A., Khurana, L. (2009) The Metabolic Syndrome in South Asians: Epidemiology, Determinants, and Prevention. Metab Syndr Relat Disord 7, 497-514.

Misra, A., Khurana, L. (2009) The metabolic syndrome in South Asians: Epidemiology, clinical correlates and possible solutions. International Diabetes Monitor 21, 92-101.

Mohan, V., Rao, G.H.R. (2007) Type 2 Diabetes in South Asians. 1st ed. New Delhi: South Asian Society on Atherosclerosis and Thrombosis

Misra, A., \& Vikram, N., K. (2008) Factor, definitions, predictive value \& Asian Indian ethnicity: Complexities of the metabolic syndrome. Indian J Med Res 127,293-296

Mabry, R.M., Reeves, M.M., Eakin, E.G., Owen, N.(2010) Gender differences in prevalence of the metabolic syndrome in Gulf Cooperation Council Countries: a systematic review. Diabet Med 27, 593-7.

Mohan, V., Deepa, R.(2006) Obesity and abdominal obesity in Asian Indians. Indian J Med Res $123,593-6$

Prasad, D.S., Kabir, Z., Dash, A.K., Das, B.C. (2011) Abdominal obesity, an independent cardiovascular risk factor in Indian subcontinent: A clinico epidemiological evidence summary. $J$ Cardiovasc Dis Res. 2,199-205.

Prasad, D. S., Kabir, Z., Dash, A. K., Das, B.C. (2010).Cardiovascular risk factors in developing countries: A review of clinico-epidemiological evidence. CVD Prev Control $5,115-23$.

Perkins, N. J., Schisterman, E.F. (2006) The inconsistency of "optimal" cut points obtained using two criteria based on the receiver operating characteristic curve. The American Journal of Epidemiology 163, 670-675

Rao, G.H.R., Thanickachalam, S. (2005) Coronary Artery Disease: Risk Promoters, Pathophysiology and Prevention. 1st ed. New Delhi: South Asian Society on Atherosclerosis and Thrombosis

Shah, B., Mathur, P. (2010) Surveillance of cardiovascular disease risk factors in India: The need \& scope. Indian J Med Res 132, 634-42

Sone, H., Mizuno, S., Fujii, H., Yoshimura, Y., Yamasaki, Y., Ishibashi S et al. (2005) Is the diagnosis of metabolic syndrome useful for predicting cardiovascular disease in Asian diabetic patients? Analysis from the Japan Diabetes Complications Study. Diabetes Care 28, 1463-1471. 
Bansal, A., Joshi, P.C. (2015). Predictor of Metabolic Syndrome: A community study from Urban Delhi, India. International Journal of Human Sciences, 12(1), 1451-1462. doi: 10.14687/ijhs.v12i1.3289

Saltiki, K., Cimponeriu, A., Lili, K., Peppa, M., Anastasiou, E., Alevizaki, M (2008) Severity of coronary artery disease in postmenopausal diabetic women. Hormones (Athens)7, 148-55.

Sam, S., Haffner, S., Davidson, MH., D’Agostino, R.B., Feinstein, S., Kondos, G, et al.(2009) Hypertriglyceridemic waist phenotype predicts increased visceral fat in subject with type 2 diabetes. Diabetes Care 32,1916-20.

Shaw, J., Zimmet, P., de Courten, M., Dowse, G., Chitson, P., Gareeboo, Het al.(1999) Impaired fasting glucose or impaired glucose tolerance. What best predicts future diabetes in Mauritius? Diabetes Care 22, 399-402.

Stamler, J., Vaccaro, O., Neaton, J.D., Wentworth, D.(1993) Diabetes, other risk factors, and 12-year cardiovascular mortality for men screened in the Multiple Risk Factor Intervention Trial. Diabetes Care 16, 434-444.

Tillin, T., Forouhi, N., Johnston, D.G., McKeigue, P.M., Chaturvedi, N., Godsland, IF. (2005) Metabolic syndrome and coronary heart disease in South Asians, African-Caribbeans and white Europeans: a UK population-based cross-sectional study. Diabetologia 48,649-656.

Tan, C.E., Ma, S., Wai, D., Chew, S.K., Tai, E.S. (2004) Can we apply the national cholesterol education program adult treatment panel definition of the metabolic syndrome to asians? Diabetes Care 27,1182-1186.

Takeuchi, H., Saitoh, S., Takagi, S., Ohnishi, H., Ohhata, J., Isobe, T et al. (2005) Metabolic syndrome and cardiac disease in Japanese men: applicability of the concept of metabolic syndrome defined by the National Cholesterol Education Program-Adult Treatment Panel III to Japanese men - the Tanno and Sobetsu Study.Hypertens Res 28, 203-208.

Tunstall-Pedoe, H., Woodward, M., Tavendale, R., A’Brook, R., McCluskey, M.K.(1997) Comparison of the prediction by 27 different factors of coronary heart disease and death in men and women of the Scottish Heart Health Study: Cohort study. BMJ 315, 722-9.

Wasir, J.S., Misra, A., Vikram, N.K., Pandey, R.M., Gupta R. (2008) Comparison of definitions of the metabolic syndrome in adult Asian Indians. J Assoc Physicians India 56 , 158-64.

Wasir, J.S., Misra, A. (2004) The metabolic syndrome in Asian Indians: the impact of nutritional and socio-economic transition in India. Met Syndr Relat Disord 2,14-23.

Wasir, J.S., Misra, A., Vikram, N.K., Pandey, R.M., Gupta, R.(2008) Comparison of definitions of the metabolic syndrome in adult Asian Indians. J Assoc Pbysicians India. 56,158-64.

Zimmet, P., Magliano, D., Matsuzawa, Y., Alberti, G., Shaw, J. (2005) The metabolic syndrome: a global public health problem and a new definition. J Atheroscler Thromb 12, 295-300. 